\section{MICROSCOPE CREATED FOR EARLY ORAL CANCER DIAGNOSIS}

A team of researchers from the University of Texas have created a portable miniature microscope designed to reduce the time taken to diagnose oral cancer.

The probe, which is around $20 \mathrm{~cm}$ long and $1 \mathrm{~cm}$ wide at its tip, could be used by doctors to diagnose oral cancer in real-time or as a surgical guidance tool; dentists could also use it to screen for earlystage cancer cells.

The probe was presented in an article in the Journal of Micromechanics and Microengineering in April $^{1}$ and has shown good agreement with images of oral cancers obtained using conventional, much slower techniques at the University of Texas Health Science Centre in San Antonio, Texas.

The probe uses a laser to illuminate areas of the sample and can view beneath the surface of tissue, creating full 3D images. It can also take a series of images and layer them on top of each other, much like the tiling of a mosaic, giving a large overall field-of-view.

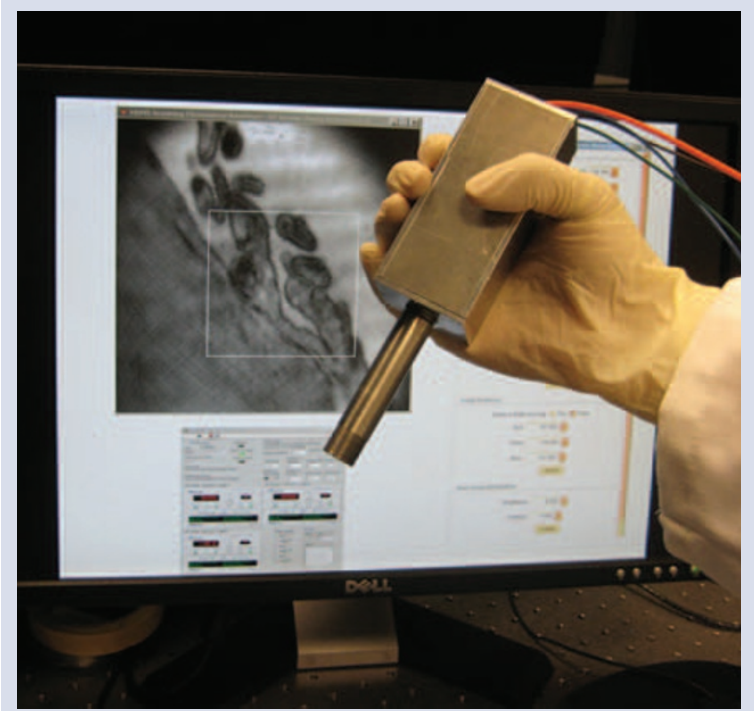

Handheld confocal imaging probe (John X. J. Zhang University of Texas at Austin)
The key component of the probe is a micromirror. Micromirrors have previously been used in barcode scanners and fibre optic switches and are controlled by a microelectromechanical system, allowing the laser beam to scan an area in a programmed fashion.

The low cost and ease of fabrication of micromirrors, along with their easy integration into electronic systems for versatile imaging operations, make them an indispensable component of the probe.

'There isn't a comprehensive programme in the US to opportunistically screen for [oral cancer], said Dr John X. J. Zhang, lead author of the study. 'Without that, late stage discovery is more common.'

Traditional methods of diagnosing oral cancer, via visual inspection, biopsy and pathology reports are time consuming, costly, invasive and painful, often leaving scars.

The researchers envisage that, with a few adjustments, the device could be built for a quarter of the price it costs to build the microscopes that are currently used in diagnosis.

1. Wang $Y$, Raj M, McGuff H S et al. Portable oral cancer detection using a miniature confocal imaging probe with a large field of view. J Micromech Microeng 2012; 22: doi: 10.1088/0960-1317/22/6/065001. Available at: $h t t p: / / i o p s c i e n c e . i o p$. org/0960-1317/22/6/065001 (Accessed 31 May 2012).

\section{UPDATE PUBLISHED ON CANCER GUIDANCE}

NHS Evidence has published a new Evidence Update, Improving outcomes in head and neck cancers. The update focuses on a summary of selected new evidence relevant to the NICE cancer services guidance published in 2004 . $^{1}$

NHS Evidence provides access to more than 300,000 reliable resources from 1,300 sources. Evidence Updates provide a regular, often annual, summary of selected new evidence published since a literature search was last conducted for the accredited guidance they relate to. They reduce the need for individuals, managers and commissioners to search for new evidence, and inform guidance developers of new evidence in their field.

Evidence Updates highlight new evidence that might impact on the most recent, accredited guidance and also provide a commentary on the likely impact.

The new Evidence Update can be accessed at: www. evidence.nhs.uk/2656/improving-outcomes-in-headand-neck-cancer-evidence-update-may-2012.pdf.

1. NICE. Improving outcomes in head and neck cancers. NICE cancer services guidance. 2004. Available at: www.nice.org.uk/guidance/CSGHN.
DIARY

100th FDI Annual World Dental Congress

Date: 29 August - 1 September 2012

Location: Hong Kong

www.fdicongress.org

17th World Congress on Dental Traumatology Science and Art: Overcoming the Limits of Knowledge Date: 10-22 September 2012 Venue: Rio de Janeiro, Brazil www.iadt-dentaltrauma.org www.sbtd.org.br

\section{PER/IADR Congress}

Date: 12-15 September 2012

Location: Helsinki, Finland

http://iadr.com/i4a/pages/index. cfm?pageid $=3955$

\section{Optimising Outcomes}

in Restorative Dentistry

Date: 20 September 2012 Venue: Symposium Hall of the College, The Royal College of Surgeons of Edinburgh Email: h.anderson@rcsed.ac.uk Telephone: 01316689239 https://ubis.rcsed.ac.uk/courses/ coursedetails.aspx?diaryld=1027

British Orthodontic

Society Conference

Date: 23-25 September 2012

Location: Bournemouth

www.bos.org.uk

DDU-Eastman

Dento-Legal Conference

Date: 28 September 2012

Location: London

Email:edi-cpd@ucl.ac.uk

www.the-ddu.com

BDTA Dental Showcase

Date: 4-6 October 2012

Venue: ExCeL London

www.dentalshowcase.com

A day with Dr Pascal Magne: no post no crown restorative dentistry: a biomimetric approach Date: 26 October 2012

Venue: Novotel St Pancras, London Telephone: 02075634590 www.bda.org/seminars

BSDHT Oral Health Conference Date: 9-10 November 2012

Venue: ACC Liverpool

www.bsdht.org.uk 